\title{
La construcción de objetos de conocimiento en artes
}

Carlos Gallegos Elías

Universidad Nacional Autónoma de México

gallegoselias@yahoo.com.mx

\begin{abstract}
"La historia es la única posibilidad (...) de captar realidades en movimiento (...) [porque] el problema no es el de formular grandes 'leyes' [leyes generales] (...) sino el de dibujar procesos característicos".

(Vilar, 1998, págs. 92-93)
\end{abstract}

Quienes asistimos a este IV Congreso Nacional sobre Investigación y Educación Superior de las Artes estamos aquí por una preocupación común: reflexionar para proponer respuestas a dos preguntas centrales de nuestro quehacer cotidiano como académicos: cómo enseñamos y cómo enseñamos a investigar. Binomio indisoluble de nuestra tarea de todos los días: investigar para hacer posible el aprender a aprender.

Nos reúne la necesidad de reflexionar juntos y dialogar sobre la pertinencia y la oportunidad de los caminos que hemos elegido en busca del conocimiento.

En los últimos años, junto con los investigadores y docentes universitarios que formamos parte de la Red Latinoamericana de Metodología de las Ciencias Sociales, hemos trabajado en buscar respuestas a las preguntas ¿Cómo investigamos? y ¿Cómo enseñamos a aprender a investigar?, dos cuestiones que están estrechamente ligadas y a las que hemos dedicado un importante espacio académico en cada uno de los Encuentros que hemos tenido, donde nos preocupa de manera relevante indagar cuál es el estado de la Investigación en Artes y Humanidades y cuáles son los distintos enfoques teóricos y metodológicos para abordar nuestros objetos de investigación y contrastar con los puntos de vista de cada uno de nuestros colegas preocupados también por responder estas interrogantes. Una inquietud presente en prácticamente todas las instituciones de educación superior de Latinoamérica donde existen formaciones profesionales e investigación en Artes y Humanidades. Este espacio que nos brinda la Red Latinoamericana de Metodología de las Ciencias Sociales es un ámbito privilegiado de intercambio de ideas y reflexiones acerca de cómo resolver los retos cotidianos del oficio de investigar y de enseñar a aprender. Un reto considerablemente más complejo que el sólo enseñar, porque implica aprender a pensar los múltiples elementos que giran en torno al mundo de la investigación en ciencias sociales, artes y humanidades.

Esta RedMet de la cual formo parte y en la que soy Coordinador del Nodo México, ha propiciado un diálogo muy fértil, donde exponemos nuestros problemas, nuestras carencias, nuestras dudas, que no sobra recordarlo, se dan de manera muy semejante en todas las instituciones de investigación y educación superior en América Latina. Es un campo cultural donde pensamos y proponemos respuestas que sometemos a la crítica de nuestros pares, con quienes dialogamos sobre la búsqueda de nuestro propio camino al conocimiento.

Hay muchas preguntas alrededor de nuestra tarea y la que está siempre presente es ¿cómo construimos el conocimiento del que disponemos hoy para entender un mundo que vive un acelerado proceso de cambio y del cual somos parte?

Para entrar en materia pienso que el proceso de producción del conocimiento es una suerte de clivage que se da a lo largo 
del tiempo, en el que poco a poco se depositan los saberes de todo tipo y en ese devenir histórico se forman capas de diferentes espesores y densidades que conforman el cauce de un río donde convergen muchos afluentes, en un cauce donde abrevamos para producir conocimiento propio.

Un proceso que en este caso, es una suerte de homenaje y reconocimiento a la herencia que arranca del momento en que Marx plantea en La Ideología Alemana que el arte no es un producto del genio, sino que es una forma de producción y que la especialización artística es fruto de la división social del trabajo y el arte, parte de una ideología, que las clases dominantes generan, aprovechan y usan para perpetuar las relaciones de clase.

En esta línea, una referencia indispensable es la concepción de Gramsci acerca del papel de los intelectuales orgánicos en la dirección cultural de una nación. Un artista es sin duda un intelectual orgánico que contribuye a definir la cultura.

Es un punto de partida que siguen puntualmente György Lukács, con su idea del arte como una visión del mundo, como una mediación entre el hombre y las cosas. Nicos Hadjinicolaou con su trabajo para explicar el arte como una expresión de la lucha de clases. T.H. Adorno con su reflexión para entender la industria cultural. Walter Benjamin con su visión sobre la obra de arte en la época de su reproductibilidad mecánica. Friedrich Antal, que nos ayuda a comprender el arte como una expresión de las condiciones sociales y políticas de una época. Arnold Hausser y Marcel Mauss, contribuyeron también a permitirnos entender la historia del arte como una expresión social.

Más cerca en el tiempo, este trabajo reconoce su deuda con la herencia de Pierre Vilar, Hugo Zemelman y por supuesto, de Pierre Bourdieu. Todos estos pensadores han construido la trama y la urdidumbre donde se entreteje lo que aquí se propondrá.
Creo estamos en un momento donde nuestros modos de intervención científica, nuestras técnicas de investigación, nuestros acercamientos a explicar la realidad de objetos de investigación en constante movimiento y transformación, pese a su alto grado de refinamiento, son notoriamente insuficientes para entender lo que ocurre hoy.

Nuestras herramientas son cada vez más precisas, tanto que nos permiten describir un fenómeno o un proceso de manera muy prolija y detallada, podemos contar de manera pormenorizada la historia de una escuela de pintura, de una corriente literaria o de instituciones de formación musical como Julliard, Curtis o IRCAM; conocer a detalle la obra de un gran constructor de instituciones como Pierre Boulez en Francia o entre nosotros, Carlos Chávez y su trabajo memorable. O bien, de autores como Maurice Bejart y su ballet del Siglo XX; Jiří Kylián y su trabajo en el Netherlands Dans Theater. Entre nosotros, Guillermina Bravo y la Academia de la Danza Mexicana; Claudia Lavista con Delfos; Miguel Mancillas con Antares. Artistas notables que han marcado un antes y un después en la historia de la danza contemporánea.

Apoyados en los avances del conocimiento informático, podemos describir un hecho, un proceso, un fenómeno e incluso, disponer de un registro estadístico muy preciso sobre casi cualquier tema. Todo eso podemos hacerlo y gracias a ello buscar comprender lo que ocurre en una realidad inimaginable hasta hace muy poco tiempo, en que el mundo de lo virtual es el espacio donde transcurre buena parte de nuestras vidas y de la de nuestros estudiantes, circunstancia que nos plantea retos extraordinarios a las instituciones y los profesores.

El conocimiento que buscamos transmitir en la escuela, en buena medida ya sólo es historia, cuya obsolescencia se da antes de que concluyan sus formaciones profe- 
sionales. Una escolarización ajena a sus vivencias de todos los días en que están, literalmente, sometidos a un bombardeo de información e imágenes, que hacen de ellos... ¿o para hacer de ellos? meros receptores pasivos sin margen para reflexionar. Como profesores, nuestro reto más complejo es cómo lograr que nuestros alumnos aprendan a procesar, a discernir, a jerarquizar y desagregar la información que reciben para que se transformen en sujetos activos del conocimiento, en sujetos capaces de crearlo o de producirlo. Creo que el efecto neto de este alud de imágenes es que inhibe la posibilidad de detenerse el tiempo necesario para procesar ese torrente de información y es esa la barrera más grande por superar.

La vida contemporánea ofrece saberes múltiples que nos han llevado a la configuración de un nuevo espacio, donde las visiones disciplinarias con las que en buena medida seguimos trabajando

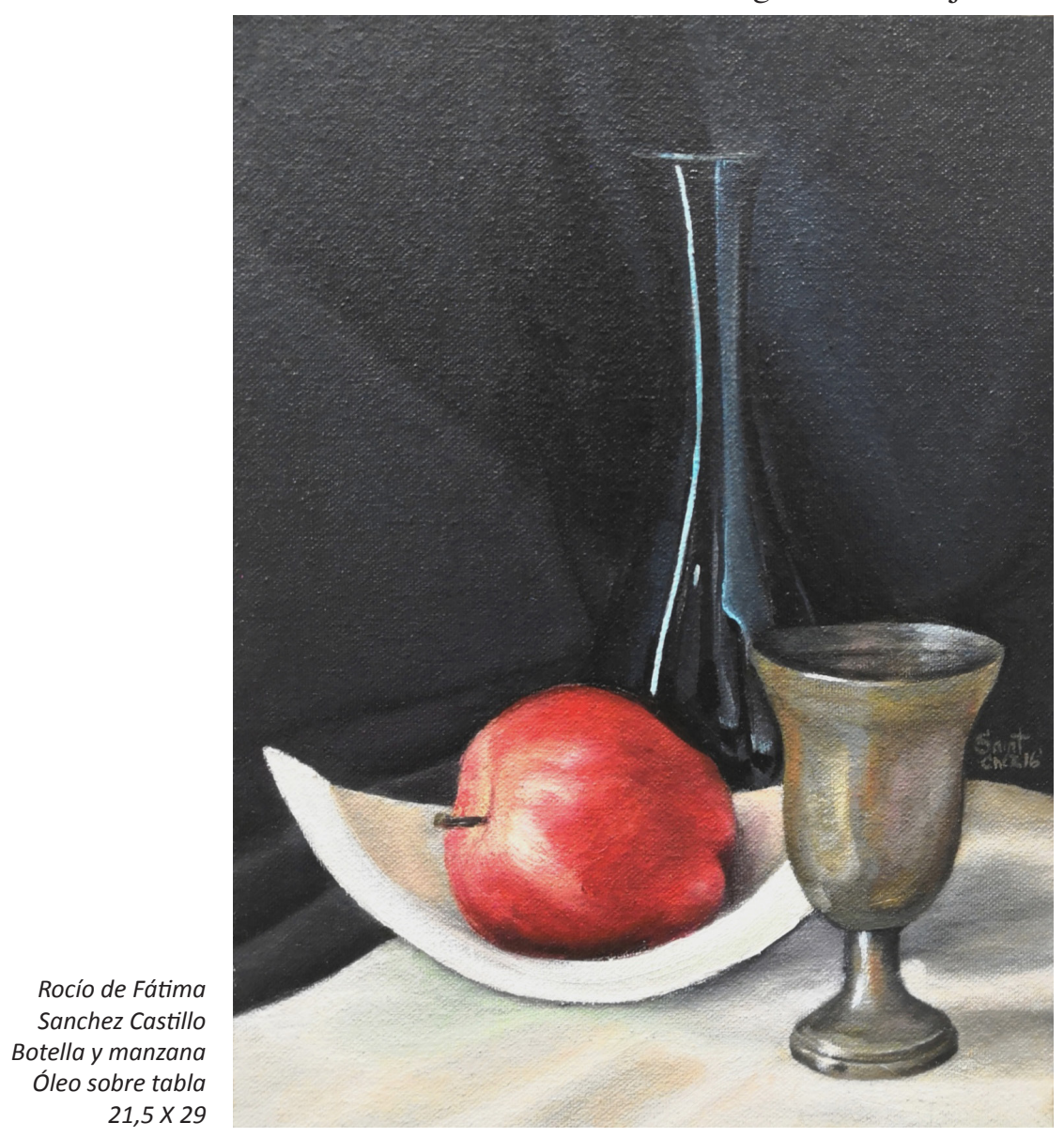

(como se evidencia en las formas de organización de nuestras instituciones educativas y en los diseños curriculares de las formaciones profesionales) son incapaces de explicar lo que ocurre.

En realidad, lo que sucede frente a nosotros es que se ha constituido un campo cultural y artístico donde se conjugan y suceden en el tiempo la interacción de múltiples perspectivas, de muchos tiempos que se dan en un mismo tiempo, de muchos procesos que se dan dentro de un proceso, configuraciones de la realidad que no podemos entender si no asumimos que la concepción tradicional del conocimiento ya es parte de nuestra historia. Punto de partida para entender lo que ocurre hoy.

El mundo que aprendimos a explicar simplemente ya no existe, en prácticamente ningún orden de nuestras vidas, lo cual vale para todos los procesos sociales en los que estamos inmersos, y entre ellos por supuesto, lo que ocurre en el campo de la creacion artística. Nos enfrentamos a realidades que desbordan los límites de los acercamientos tradicionales de carácter disciplinario y nos pone frente al reto de responder a una pregunta inquietante: ¿Cómo dar cuenta entonces de esto nuevo que emerge?

La respuesta radica en atrevernos a pensar lo no pensado, ir más allá de los límites establecidos por los paradigmas con los cuales trabajamos para reflexionar lo que está más allá de los lindes de las disciplinas y construir una visión transdisciplinar que trascienda las estrechas fronteras tradicionales de las disciplinas, caminar entre sus intersticios. Tengamos muy claro que mantenernos dentro de los límites establecidos sólo nos puede conducir a resolver los problemas y las preguntas planteadas por otros, que construyeron sus respuestas en un momento y un espacio distintos. Como con frecuencia ocurre cuando "dirigimos" los proyectos de investigación de nuestros estudiantes. 
Tenemos un gran obstáculo que nace de una suerte de conservadurismo académico con el cual nos enfrentamos todos los días: la rígida estructura organizativa de nuestras instituciones y en la resistencia al cambio, pero al mismo tiempo, está a nuestro alcance otro camino posible: orientar a nuestros estudiantes a ver de otra manera el objeto; a verlo desde la historia de lo que queremos investigar. Entender nuestro objeto es el punto de partida necesario para verse de otra manera como investigadores, encontrar, reconocer y desarrollar sus posibilidades. Es decir, generar en ellos la necesidad y la conciencia de convertirse en un sujeto activo que hace preguntas, conjetura y duda de las respuestas posibles, que vuelve siempre la pregunta de investigación como su herramienta privilegiada. Construir las preguntas posibles es la clave de la investigación.

Tendrá que preguntarse a sí mismo quién es como sujeto, cuál es el campo problemático de su investigación, cuál es su problema y su pregunta central de investigación, cuál es su lugar en el campo, desde dónde se coloca, por qué y para qué está ahí, por qué y para qué investiga. Cuál es su propia historia y su camino al conocimiento.

A lo largo de la investigación, una y otra vez, nuestros estudiantes deberán volver a preguntarse sobre su objeto y cuál es el sentido de indagar sobre él, porque conforme avanza la investigación, las respuestas serán distintas.

Es decir, deberán observar que... " $a$ través del tiempo y también a través del espacio (...) el movimiento de la historia resulta de la coexistencia de los campos y de la interacción de los factores, en un movimiento continuo -frecuentemente rítmico, 'coyuntural' - de relaciones cuantitativas y cualitativas" (Vilar, 1992, pág. 32).

Y desde ahí, desde esa visión construir el objeto de conocimiento. Una tarea que supone una visión comprehensiva del objeto elegido, de las preguntas cuyas respuestas debe indagar, desde la historia del objeto y preguntarse cómo y por qué ocurre lo que ocurre.

Me gustaría subrayar que desde mi perspectiva el mundo del arte, el campo de la producción artística, es uno de los más complejos porque ahí se expresan y confluyen muchos elementos, ahí interactúan múltiples agentes y procesos. Uno fundamental: el avance del conocimiento científico, que nos permite disponer de herramientas cada vez más desarrolladas y capaces de cumplir múltiples funciones para producir y reproducir la obra de arte, para producir y reproducir innovaciones constantes en las formas y resultados de las expresiones artísticos, formas contemporáneas que las nuevas tecnologías nos permiten reproducir prácticamente sin límite.

También es de tener en cuenta la acción de los proyectos y programas institucionales públicos y privados que apoyan la creación artística, que se expresan en diversas configuraciones y ámbitos de acción. Por otra parte el papel del mercado del arte y quienes concurren a él como agentes de intermediación, como consumidores y espectadores.

En fin, hay muchos agentes como los que enlisto que juegan y operan en el campo, cada uno con sus propios intereses, complejidad que sólo puede cumplirse como un ejercicio interdisciplinario.

Pensar al sujeto creador como parte de una unidad indisoluble con el objeto de investigación supone un ejercicio que demanda una visión que reconozca el anverso y reverso de éstos; que reconozca que no es posible indagar al interior de un objeto, de un proceso e ignorar lo que lo generó, lo que ocurre antes y al exterior. Es necesario comprenderlo como la unidad compleja que es, como un proceso que resulta de otros procesos.

No se trata de ignorar la tradición teórica 
que nos ha dado las herramientas y técnicas de investigación de las que hoy disponemos, que han alcanzado un altísimo grado de refinamiento. Lo que planteo es que esa tradición bien mirada, pocas veces nos permite ir más allá de un mero acercamiento morfológico al objeto.

Tampoco propongo en manera alguna, dejar fuera ese saber hacer desde distintas ópticas, porque la tarea es lograr que desde ese saber hacer podamos construir conocimiento, desde el dominio que hemos alcanzado en el pensamiento parcelado en disciplinas, resignificarlo en función de nuestras necesidades de hoy.

Asumir que nuestra tarea es comprender y explicar los dinamismos que están detrás de las nuevas configuraciones en todos los ámbitos de la realidad: sociales, económicos, políticas y culturales, nuevas articulaciones que constituyen esos nuevos objetos que emergen en el mundo contemporáneo.

Objetos de investigación, que son realidades en movimiento, que al mismo tiempo que son están siendo. Realidades que se expresan en planos múltiples, en interacciones de distintas dinámicas disciplinarias, tal como ocurre en una puesta en escena en teatro, danza, cine, música, en una producción literaria, en la creación plástica.

La creación artística es la concreción, la articulación de diferentes dinamismos, el punto que se expresa en un momento de un movimiento continuo de interacciones que coexisten en un mismo instante.

Dar cuenta del momentum de la producción artística es dar cuenta de su historia, pero no entendida como expresión de leyes generales, sino abierta a múltiples determinaciones que sólo podemos identificar plenamente al conocer cómo se expresa la conjunción de todos los procesos que confluyen para hacer posible un objeto artístico.

Es la realidad que vemos al asistir a una puesta en escena, al leer literatura o al ver una pintura. Proceso que siempre es la conjugación de muchos desarrollos, donde el reto es identificar y saber ver lo que no se ve: las articulaciones y mediaciones que han hecho posible esa expresión artística, cualquiera que sea su naturaleza. La tarea del investigador es saber reconocer, identificar, explicar y desagregar los producentes y lo producido.

Podemos reconocerlo si asumimos que quien crea, sujeto individual o sujeto colectivo, es un sujeto social concreto que genera una obra artística, cuyas claves de comprensión están en conocer el proceso de producción, resultado social del vínculo que se establece entre las posibilidades y cualidades del artista y su entorno. Resultado de una cultura que no es lo que se tiene, sino más bien en lo que se ha devenido y la competencia artística es la expresión, la condensación sublimada del dominio del conjunto de los medios de la apropiación específica de la obra de arte (Bourdieu, 2002, pág. 216).

Sujeto individual o colectivo, en el cual la creación es siempre la concreción de la confluencia de un habitus socialmente constituido que resulta de una determinada posición ya instituida o posible en la división del trabajo de producción cultural; ubicación donde el artista realiza su obra y se hace a sí mismo como tal. En suma, el habitus, tal como nos plantea Bourdieu (1984, pág. 228).

El artista no es un ser excepcional, no es una persona singular, es la expresión de todo el conjunto del campo de la producción artística, un campo que supone, en palabras de Bourdieu (1984) "una relación de autonomía relativa, más o menos grande según las épocas y las sociedades, con los grupos donde se reclutan a los consumidores de sus productos" (pág. 229).

Siempre en palabras de nuestro autor, en un texto que condensa de manera ejemplar su visión sobre el arte, nos plantea:

La sociología de las obras culturales debe tomar como objeto el conjunto de las relaciones (...) entre el artista y los 
demás artistas, y, de manera más amplia, el conjunto de los agentes envueltos en la producción de la obra o, al menos, en la del valor social de la obra (los críticos, directores de galerías, mecenas, etcétera) (Bourdieu, 1984, pág. 227).

Todo lo cual conforma un campo donde el creador es un productor social como muchos otros, es un agente más que juega en un campo cultural donde tiene sentido su trabajo, donde es valorado e identificado, descifrado por quienes tienen las claves de su comprensión, que sólo se comprende cabalmente si se asume que su historia es un hecho socialmente construido.

\section{Donde:}

La autonomía del artista encuentra su fundamento no en el milagro de su genio creador, sino en el producto social de la historia social de un campo relativamente autónomo, de métodos, técnicas, lenguajes, etcétera. La historia es la que define los medios y los límites de lo pensable y hace que lo que ocurre en el campo no sea nunca el reflejo directo de las limitaciones o demandas externas, sino una expresión simbólica (...) [de] la lógica propia del campo" (Bourdieu, 1984, pág. 235).

Así que el sujeto de la producción artística y de su producto no es el artista, no es un sujeto individual: es la expresión de un sujeto colectivo. Los productores de obras consideradas artísticas son sobre todo el resultado de la acción colectiva de los agentes que tienen intereses en el arte, de todos aquellos a quienes interesa el arte y su existencia, que viven del arte: críticos, coleccionistas, académicos, art dealers, conservadores, historiadores del arte y encargados de su gestión (Bourdieu, 1984, págs. 237-238).

Todo lo cual constituye el campo artístico, un campo cultural donde concurren muchos agentes; pero dos esenciales: el productor y quien tiene los medios para apropiarse del producto artístico, apropiación cuyo significado no sólo significa la

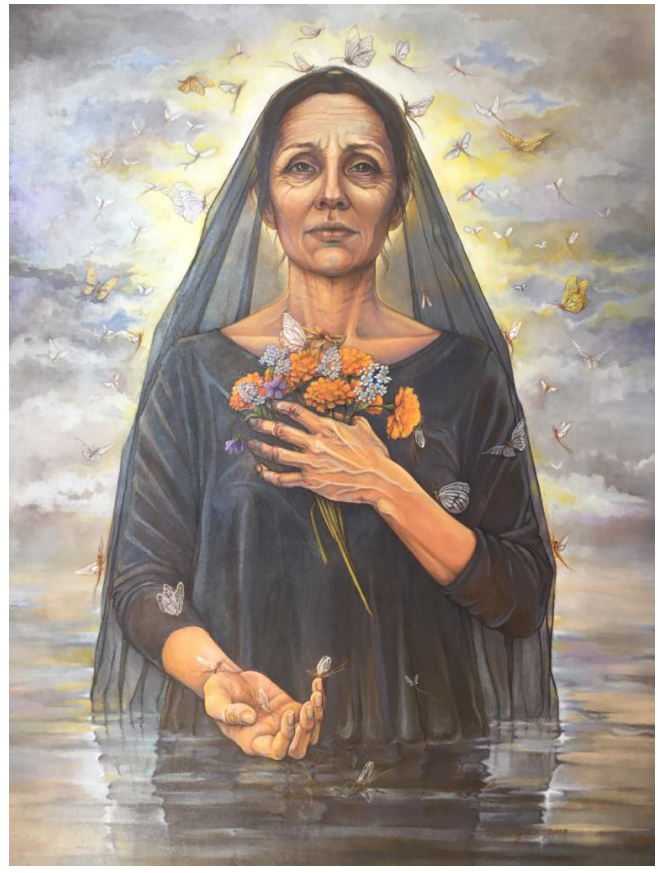

Marcela García Figueroa Óleo sobre tela

apropiación económica, sino también su apropiación simbólica, lo cual se traduce en la posibilidad de comprenderla, descifrarla, valorarla y ubicarla en términos de una taxonomía reconocida y aprende, que dota de sentido a la obra artística porque la reconoce como parte de un espacio y como expresión de un tiempo determinado.

Están en juego dos formas de articulación de realidades que Pierre Bourdieu llama competencias (Bourdieu, 2002, págs. 197-198), las del artista como productor, como expresión de su dominio de las técnicas y herramientas necesarias, de sus saberes y sus destrezas que se concretan al producir la obra de arte. Así ocurre en cualquier ámbito, en la literatura, en las artes escénicas, en las artes plásticas, en la música, y aquellas de quien tiene los códigos necesarios para entender y apropiarse de la obra de arte, que sólo existe en la medida en que es descifrada y es posible apropiársela.

Posibilidad, también construida por quienes pueden apropiársela porque le reconocen valor y tienen los medios, los conocimientos y una formación que ha desarrollado las disposiciones necesarias, 
que corresponden siempre a una condición de clase.

Disposiciones que fueron constituidas y establecidas a lo largo del tiempo por la educación familiar y escolar como una actitud incorporada, que se traduce en el conocimiento de los lenguajes, los códigos, las taxonomías y clasificaciones que hacen posible leer la obra artística, comprenderla y dialogar con ella.

Actitud que sólo se entiende si ubicamos la obra artística en el contexto en que se produce, en su tiempo y su espacio.

Modos de ver que se construyen en el entorno familiar y en la escuela, donde uno aprende el orden de las cosas, las jerarquías, a clasificar por escuelas, por corrientes de pensamiento, por autores, por estilos artísticos, por épocas, en suma, la historia del objeto, que va de las percepciones más elementales que se aprenden en la familia y desde los niveles iniciales de la formación escolar, hasta los aprendizajes más complejos y sofisticados que permiten distinguir los matices de la luz, la composición del sonido o del color y los meandros del lenguaje.

Una cultura refinada, una "disposición cultivada, como actitud duradera (...) que implica el reconocimiento del valor de las obras de arte y la aptitud para apropiarse esas obras por medio de categorías genéricas" (Bourdieu, 2002, pág. 209), lo cual sienta las bases para transitar a una percepción muy elaborada, una mirada advertida capaz de ver y reconocer un lector informado capaz de disfrutar la literatura o un espectador informado capaz de reconocer los vínculos y sus preferencias. Circunstancia que en una sociedad dividida en clases sólo tiene sentido para una minoría informada que, como consecuencia de su herencia familiar, intelectual y escolar, ha podido acceder a ese acervo; una minoría cultivada para quienes ese conocimiento que es una construcción social, aparece como algo que le es propio. Un cúmulo de valores que son imagina- dos y presentados como propios y exclusivos de su condición de clase.

Ignorar que esa distinción, que el gusto es una construcción social, permite ser presentada como un atributo o una suerte de gracia inmanente que viene con el nacimiento, mientras que la realidad es que se trata -nunca está de más insistir- de un resultado más del acceso desigual a la cultura, una expresión más de la desigualdad social.

Explicación igualmente válida para los creadores artísticos que en gran medida se perciben a sí mismos como seres excepcionales, dotados de cualidades, donde el artista posee un don, un aura, una especie particular de genio depositario de una suerte de atribución mágica que le fue otorgada al nacer y lo distingue del otro. Excepcionalidad que sirve como fundamento explicativo a un incontable número de investigaciones en la historia del arte que presenta al artista como héroe, hagiografías de un santoral artístico. $\mathrm{Si}$ el objeto artístico es un producto social, como aquí hemos dicho y reiterado, entonces desde una perspectiva metodológica y si pensamos que el arte es un producto social y que los artistas y creadores y el objeto artístico son expresiones de un momento donde se conjugan y condensan distintas historias que ocurren en un espacio que explicamos como campo artístico cultural, entonces tenemos que preguntarnos: ¿Cuáles son las interrogantes cuyas respuestas debemos buscar? ¿Dónde y cómo se producen las expresiones del arte? ¿Cómo pensarlas?

El objeto artístico se genera en la confluencia de dos procesos que se conjugan: la construcción del campo y la construcción del habitus:

El mundo del arte (...) es (...) un microcosmos que (...) obedece a leyes sociales que le son propias (...) es un mundo que tiene su propia ley (nomos), en el cual hay apuestas sociales, luchas, relaciones de fuerza, capital acumulado (...) capi- 
tal simbólico que puede producir efectos simbólicos, pero también económicos (...) y lo que está en juego es la acumulación del capital simbólico " (Bourdieu, 2010, págs. 37-38).

Es un campo que resulta de una paulatina acumulación de recursos colectivos, donde el papel de la escuela, cualquier escuela aunque no esté dedicada a la formación artística es proporcionar los elementos para acceder a esos recursos aunque de manera muy desigual porque su apropiación se da en función de la historia de la clase social a la cual pertenece el alumno, diferenciación social que está antes de la escuela y después de la escuela.

Es en ese campo donde la familia y la escuela han construido la historia de cada individuo, donde se ha construido el habitus, ese conjunto de disposiciones individuales que articulan al sujeto individual con el sujeto colectivo. Es en esa confluencia donde se expresan las historias de cada uno, donde se aprende a ver, a oír, a dominar los lenguajes (Bourdieu, 2010, págs. 39-40).

Donde se aprenden los códigos que permiten interactuar socialmente y entre ellos, los lenguajes que dan paso a la creación artística; herramientas para crear y reconocer el arte que debe entenderse también como una expresión más de la diferenciación social y la dominación.

Hermosillo, Sonora, Febrero 2019.

\section{Bibliografía}

Bourdieu, P. (1984). Sociología y cultura. México: Grijalbo.

Bourdieu, P. (2002). Elementos de una teoría sociológica de la percepción artística. En D. Navarro, Image 1. Teoría francesa y francófona del lenguaje visual y pictórico (pág. 238). Cuba: Casa de las Américas.

Bourdieu, P. (2010). El sentido social del gusto. Elementos para una sociología de la cultura. Argentina : Siglo XXI.

Vilar, P. (1998). Pensar la historia. México: Instituto Mora.

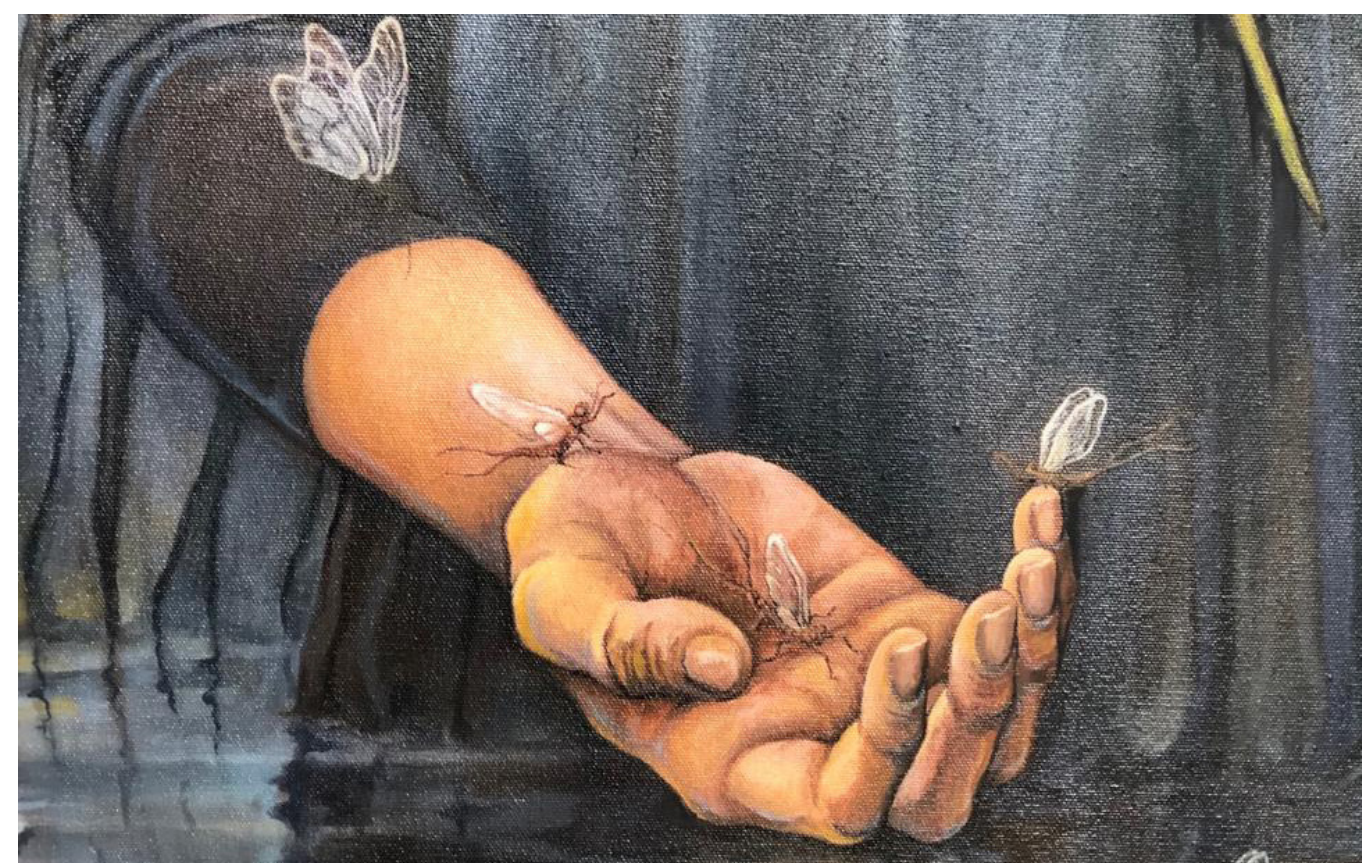

Marcela García Figueroa Óleo sobre tela (fragmento) 